\title{
To analyze the suitability of wheat and maize in Mingora Swat of Khyberpakhtunkhwa using crop growth index
}

\author{
Riaz Khan ${ }^{1}$, Nangial Khan ${ }^{2 *}$, Zia Ullah ${ }^{1}$, Shabi Ul Hassan ${ }^{3}$, Talha \\ Jan $^{1}$, Sohail ${ }^{1}$, Farooq Nawaz ${ }^{2}$ and Junaid Ahmad ${ }^{2}$ \\ 1. Department of Water Management, The University of Agriculture, Peshawar-Pakistan \\ 2. Department of Agronomy, The University of Agriculture, Peshawar-Pakistan \\ 3. Department of Environmental Sciences, COMSATS Institute of Information Technology, Abbottabad- \\ Pakistan \\ *Corresponding author's email: nangialkhan@aup.edu.pk
}

Citation

Riaz Khan, Nangial Khan, Zia Ullah, Shabi Ul Hassan, Talha Jan, Sohail, Farooq Nawaz and Junaid Ahmad. To analyze the suitability of wheat and maize in Mingora Swat of Khyberpakhtunkhwa using crop growth index. Pure and Applied Biology. Vol. 7, Issue 4, pp1228-1233. http://dx.doi.org/10.19045/bspab.2018.700142

\begin{tabular}{llll}
\hline \hline Received: 24/04/2018 & Revised: 23/08/2018 & Accepted: 27/08/2018 & Online First: 31/08/2018 \\
\hline
\end{tabular}

\section{Abstract}

A research study was carried out at Mingora Swat of Khyber Pakhtunkhwa to find Growing Degree Days of wheat and maize and Crop Growth Index using long term climatic data (19712010).The study will expound the classification according to the research methodology which in response will help to the policy makers and the agriculturist to grow the crops suiting to the study area. The climatic data used for research was acquired from Pakistan Meteorological Department (PMD) Islamabad. The available Growing Degree Days of wheat and maize were classified by subtracting the base temperature from average temperature. Decade-wise and overall trend of GDD were calculated by using simple linear regression analysis. Based on 40 years data increasing trend was observed for the GDD of wheat and maize at Mingora (Swat). Based on the Crop Growth Index $\left(\mathrm{I}_{\mathrm{cg}}\right)$ limits Mingora swat was classified as Moderately Adequate.

Keywords: Crop Growth Index; GDD; Maize; Mingora Swat; Wheat

\section{Introduction}

Pakistan can be divided on the basis of climate into different zones such as arid, semi-arid, sub-humid and humid, in other words from a drier to wetter. The naming of climatic characteristics of a region helps in assessment of agro-climatic potential, the plant and animal variety, which are situated in that area and selection of crop-varieties, which are able to produce more yields. Agro-climatic classification enables us to draw boundaries on the basis of homogeneity. The agriculture not only depends on rainfall but also depends on water, which comes from melting of snow and ice. This water is used for irrigation of agricultural lands when it reaches rivers, dams and canals. On the western side of Pakistan, Arabian Sea is located while in northern side there are Himalaya and Karakoram mountains. These mountains are covered with snow and they act like water tanks over the top, which provide water when needed. The low temperatures in the mountainous areas have negative impact on agriculture, which decreases the 
growing stage for the winter period crops. In the mountainous areas, the winter crops like wheat cannot reach to maturity; the crop is harvested before the time and used as fodder for animals [1]. The impacts of climate change are more critical in South Asia and may result in $50 \%$ reduction in wheat yield. Due to climate change, the rainfall decreases and temperature increases. Amongst the countries that are going to be damage by climate change, Pakistan is on $28^{\text {th }}$ number. In the World Bank's list, Pakistan is included in 12 extremely exposed countries to climate change. In Pakistan, due to climate change temperature will rise and the severe rains can reduce the production. In the northern region of Pakistan, the rains will increase and the recent floods are due to extreme and uneven rains. In Asia the variation in rainfall has increased annually in a few past decades. The declining trends in rainfall patterns along Pakistan's coastal areas and arid plains have been observed [2]. According to Pakistan Meteorological Department, main parts of Pakistan experience dry climate, and receive less than $250 \mathrm{~mm}$ of rainfall [3].

The Pakistan is a populated country its economy is based on Agriculture and it is highly exposed to natural disaster. Therefore, it is important to find out the trends of rainfall in different climate zones of Pakistan over the last four decades. The Pakistan Meteorological Department reported that in the year 2012 has been a slow but steady change occurred in the position where more rainfalls occurred. In the past, decade's monsoon rains fell intensively over the Punjab, but slowly and gradually the concentration of rainfall has moved to north and west of Khyber
Pakhtunkhwa [3]. In Pakistan the climate change is a big challenge for the agrarian economy. Climate changes have disturbed the agriculture production. Arid areas are more at risk to climate change due to increase in temperature and decreased in rainfall production in arid area significantly reduced.

\section{Materials and methods}

In Khyber Pakhtunkhwa, there exist all types of climates, which are different from place to place, the northern region has humid while the southern region have dry climate. Due to this changeable climatic condition, it is divided into different agro climatic zones. The present study was carried out to analyze the agro-climatic condition in the Mingora Swat of Khyber Pakhtunkhwa.

\section{Description of the study area}

Khyber Pakhtunkhwa has an extensive range of physical and climatic environment. The present study was carried out at Mingora (Swat).Map in (Figure 1) clearly shows the selected location. Mingora (Swat) is situated in the northern region of Khyber Pakhtunkhwa. The average minimum temperature in winter is $-2^{\circ} \mathrm{C}$, but the maximum temperature was $10{ }^{\circ} \mathrm{C}$. Mingora (Swat) has hot and pleasant climate, more rainfall occurs in winter season as compare to summer. The main river flows is river Swat. The water flow in river is due to snow fall occurred in winter on the mountain of Kalam, Malam Jabba, Madyan and Bahrain. The average temperature remains $18{ }^{\circ} \mathrm{C}$, while the average rainfall is $898 \mathrm{~mm}$ per year. Information about altitude, latitude, longitude and crop data of the selected station is given in (Table 1).

Table 1. Description of the selected location wheat and maize data

\begin{tabular}{|c|c|c|c|c|c|c|c|c|c|}
\hline Location & \multirow{2}{*}{$\begin{array}{c}\text { Altitude } \\
(\mathbf{m})\end{array}$} & \multirow{2}{*}{$\begin{array}{c}\text { Latitude } \\
\left({ }^{\mathbf{0}} \mathbf{N}\right)\end{array}$} & \multirow{2}{*}{$\begin{array}{c}\text { Longitude } \\
\left({ }^{\mathbf{0}} \mathbf{E}\right)\end{array}$} & $\begin{array}{c}\text { Planting } \\
\text { date }\end{array}$ & $\begin{array}{c}\text { Harvesting } \\
\text { date }\end{array}$ & $\begin{array}{c}\text { Growth } \\
\text { Period }\end{array}$ & $\begin{array}{c}\text { Planting } \\
\text { date }\end{array}$ & $\begin{array}{c}\text { Harvesting } \\
\text { date }\end{array}$ & $\begin{array}{c}\text { Growth } \\
\text { Period }\end{array}$ \\
\hline $\begin{array}{c}\text { Mingora } \\
\text { (Swat) }\end{array}$ & 984 & 34.79 & 72.27 & $5 \mathrm{Nov}$ & 5 May & $\begin{array}{c}180 \\
\text { Days }\end{array}$ & $1-J u l y$ & $28-$ Oct & 120 \\
Days
\end{tabular}




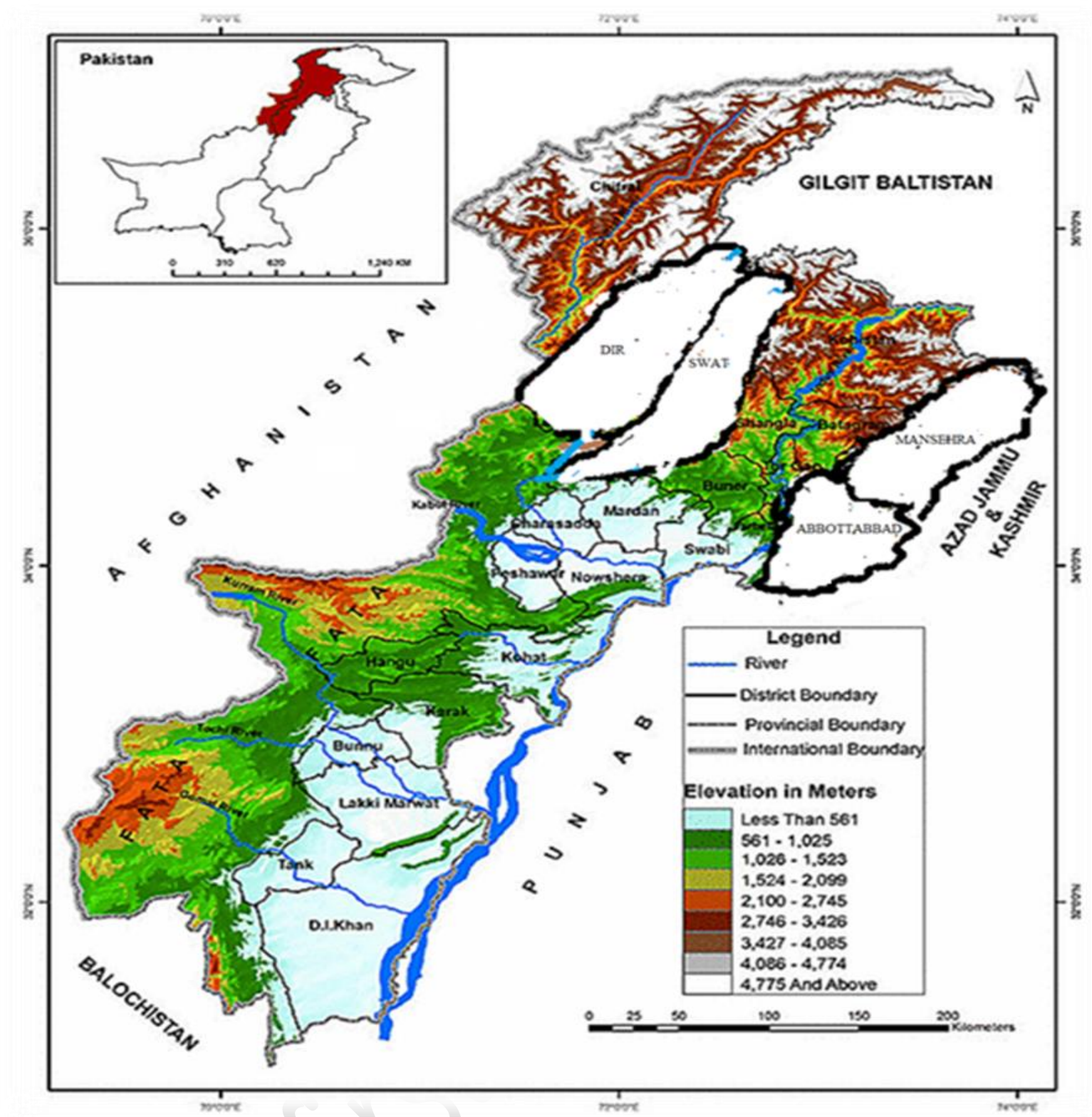

Figure 1. Map of Khyber Pakhtunkhwa showing selected stations (http://maps.onepakistan.com.pk/khyber-pakhtunkhwa.php)

\section{Crop suitability analysis}

For the crop suitability analysis the crop growth index was calculated for both wheat and maize crop. The crop growth index is defined as the ratio between available growing degree days and that of the required. The crop growth index $\left(\mathrm{I}_{\mathrm{cg}}\right)$ is given below

$$
\mathrm{I}_{\mathrm{cg}}=\frac{\mathrm{GDD} \text { available }}{\text { GDD required }}
$$

The required GDD for wheat crop was 1800 while for maize crop was 2700 [4]. According to the classes which were determined by [5] used for the preparation of maps are as under (Table 2):

Table 2. Crop growth index classes

\begin{tabular}{|c|c|}
\hline Classes & $\mathbf{I}_{\mathbf{a}}$ limits \\
\hline Deficit & $<0.5$ \\
\hline Moderately adequate & $0.5-1.0$ \\
\hline Adequate & $1.05-1.5$ \\
\hline Excess & $>1.5$ \\
\hline
\end{tabular}




\section{Growing degree days (GDD)}

GDD is defined, as the amount of heat increase used to predict plant development rates in an area with supposition that plant growth is widely influenced by ambient temperature in the absence of extreme conditions such as drought or disease. GDD can be calculated as:

GDD $=\frac{\text { Tmax }+ \text { Tmin }}{2}-$ Tbase $(2)$

Where:

$\mathrm{T}_{\max }=$ Daily highest temperature

$\mathrm{T}_{\min }=$ Daily lowest temperature

$\mathrm{T}$ base=Temperature below which the crop growth stops

$\mathrm{T}_{\text {upper }}=$ Upper temperature

If $\mathrm{T} \min <\mathrm{T}$ base, then $\mathrm{T} \min =\mathrm{T}$ base

If $\mathrm{T} \max >\mathrm{T}$ upper, Then $\mathrm{T} \max =\mathrm{T}$ upper

The base temperature calculated for wheat crop was $0{ }^{\circ} \mathrm{C}$ while the base temperature for maize crop was measured $8{ }^{\circ} \mathrm{C}$. For wheat crop the upper temperature was $26^{\circ} \mathrm{C}$ while it was $30^{\circ} \mathrm{C}$ for the maize crop [6] decade-wise and long term trend analysis in GDD was calculated by using simple linear regression equation. Considered correlation coefficients(r) were compared with table values at $5 \%$ probability to verify its statistical significance [7]

\section{Results and discussion}

A research study was carried out at Mingora Swat of Khyber Pakhtunkhwa to determine the suitability of wheat and maize using crop growth index

\section{Analysis of growing degree days (GDD) of wheat and maize \\ GDD of wheat in Mingora (Swat)}

(Table 3) and (Figure 2) explain the variation in GDD of wheat crop at Mingora (Swat). There was increasing trend during the $1^{\text {st }}$ decade (1971-1980). The maximum value (2191) of GDD was observed in the year 1976, while the minimum (1768) in 1971. Similarly, an increasing trend was observed in the second decade (19811990). The maximum value was (2398) measured in the year 1985 and minimum (1983 in 1984. The $3^{\text {rd }}$ decade (1991-2000) also showed an increasing trend with maximum (2363) in the year 1999 and minimum (1864) in 1995. Similarly, the increasing trend was observed during the last decade (2001-2010) with maximum value (2392) in the year 2005 and minimum (2166) in 2002. Based on 40 years data (1971-2010), an increasing trend was observed in GDD. The overall increase in GDD was statistically significant. The main reason of increases of temperature in the past 40 year was due to increase of greenhouse gases such as carbon dioxide, sulfur dioxide and nitrogen dioxide. Due to the increase in temperature, the growth and yield of the wheat crop was decreased. The increase of temperature is the cause of global warming, which was earlier apparent in various parts of the world, and also in our country [8].

\section{GDD of maize in Mingora (Swat)}

(Table 4) and (Figure 3) explain the variation in GDD of maize at Mingora (Swat). There was a declining trend in $1^{\text {st }}$ decade (1971 -1980). The highest value was (2432) was measured in the year 1972 and lowest (1790) in 1974. However, an increasing trend was observed during of the second decade (1981-1990). The maximum value (2052) was observed in the year 1990 and minimum (1747) in 1986. Similarly, the $3^{\text {rd }}$ decade (1991-2000) also showed an increasing trend. The maximum value (1980) was found in the year 1999 and lowest (1865) in 1994. The last decade (2001-2010) also showed an increasing trend the highest GDD (1962) was found in the year 2010 and lowest (1830) in 2002. Based on 40 years data (1971-2010), a declining trend was observed in GDD. The overall decrease in GDD was statistically significant. The decrease of GDD could be due to decrease in average temperature during the growing season of maize crop. The decreases of temperature were due to the altitude and more average rainfall at Mingora (Swat) station. 
Table 3. GDD of wheat in Mingora (Swat)

\begin{tabular}{|c|c|c|c|c|c|c|c|}
\hline Decade & Min. & Max. & Avg. & Slope & $\mathbf{R}^{\mathbf{2}}$ & $\mathbf{R}$ & Significance \\
\hline $1971-1980$ & 1768 & 2191 & 2043 & 17.24 & 0.23 & 0.47 & $\mathrm{~ns}$ \\
\hline $1981-1990$ & 1983 & 2398 & 2220 & 18 & 0.19 & 0.43 & $\mathrm{~ns}$ \\
\hline $1991-2000$ & 1864 & 2263 & 2121 & 15 & 0.11 & 0.33 & $\mathrm{~ns}$ \\
\hline $2001-2010$ & 2166 & 2392 & 2275 & 13.42 & 0.29 & 0.53 & $\mathrm{~ns}$ \\
\hline Overall (1971-2010) & 1768 & 2398 & 2168 & 6.48 & 0.28 & 0.52 & $*$ \\
\hline
\end{tabular}

*significant at 0.05 probability level; ns: non-significant

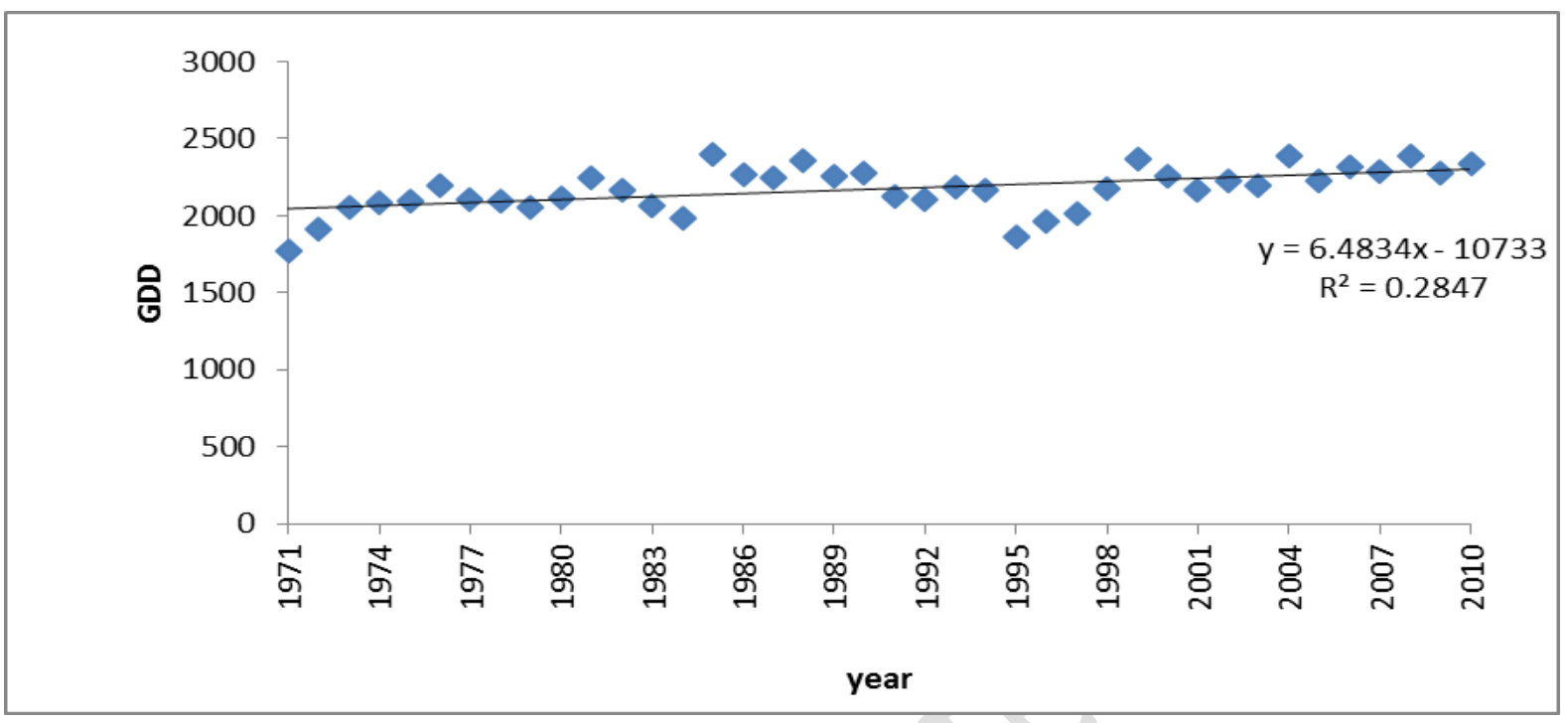

Figure 2. Long-term (1971-2010) variation in GDD of Wheat in Mingora (Swat)

Table 4. GDD of maize in Mingora (Swat)

\begin{tabular}{|c|c|c|c|c|c|c|c|}
\hline Decade & Min. & Max. & Avg. & Slope & $\mathbf{R}^{\mathbf{2}}$ & $\mathbf{R}$ & Significance \\
\hline $1971-1980$ & 1790 & 2432 & 2051 & -17.51 & 0.11 & 0.33 & Ns \\
\hline $1981-1990$ & 1747 & 2052 & 1939 & 8.43 & 0.06 & 0.24 & Ns \\
\hline $1991-2000$ & 1865 & 1980 & 1911 & 18.35 & 0.27 & 0.51 & Ns \\
\hline $2001-2010$ & 1830 & 1962 & 1911 & 10.67 & 0.35 & 0.59 & Ns \\
\hline Overall (1971-2010) & 1747 & 2432 & 1961 & -4.07 & 0.14 & 0.37 & $*$ \\
\hline
\end{tabular}

*significant at 0.05 probability level; ns: non-significant

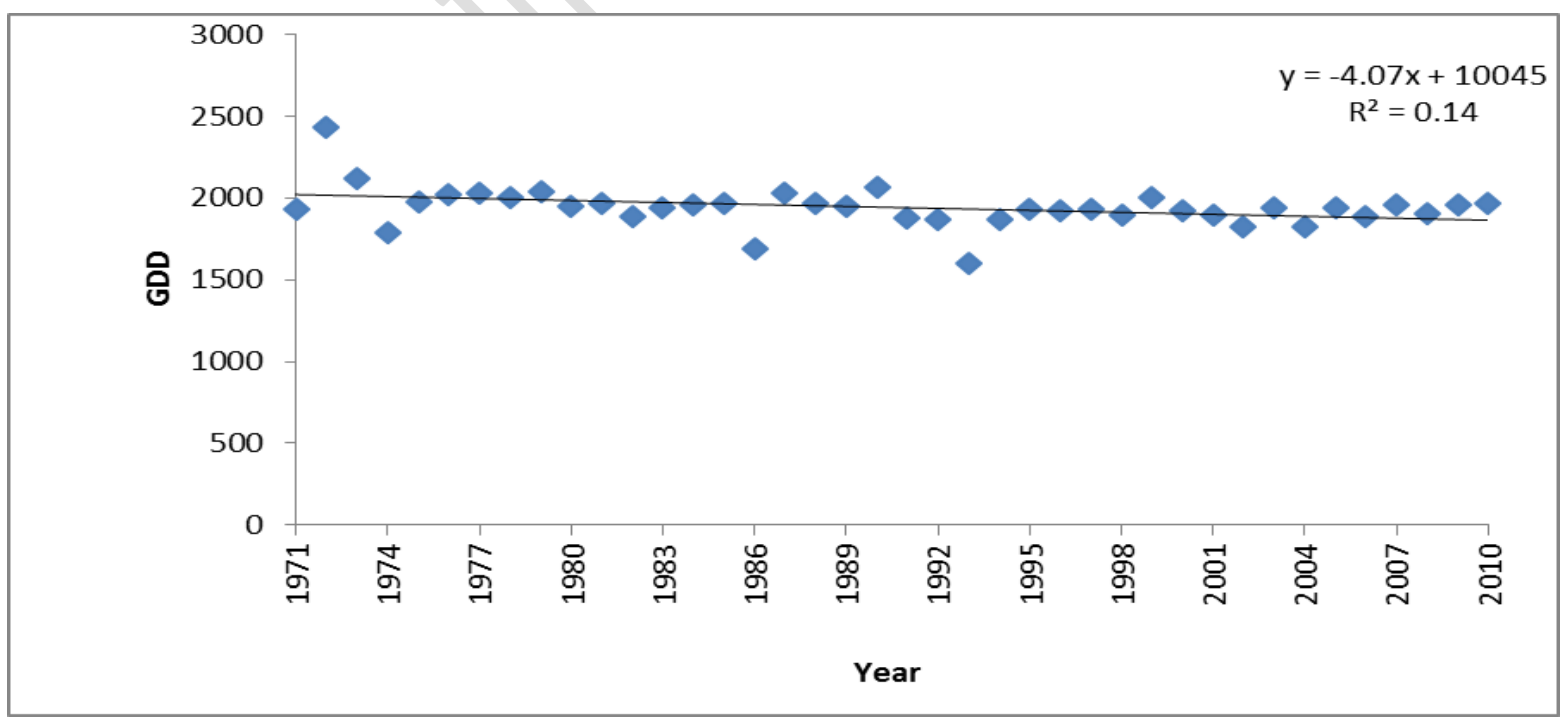

Figure 3. Long-term (1971-2010) variation in GDD of maize in Mingora (Swat) 
Crop suitability analysis Crop growth index $\left(I_{\mathrm{cg}}\right)$ of wheat

(Table 5) presents the $\left(\mathrm{I}_{\mathrm{cg}}\right)$ classes of the selected location. The maximum $\mathrm{I}_{\mathrm{cg}}$ (1.33) of wheat was calculated for Mingora Swat, while the minimum was (0.98). The lowest CGI was due to the low temperature in the month of January and February. Based on the CGI limits, Mingora Swat was classified as Adequate. These results are in agreement with Roohi et al. [5], who also found that the available GDD in the selected location was Adequate. The climate of this target location was good for the growth of wheat.

Table 5. Crop growth index ( $\left.I_{\mathrm{cg}}\right)$ of wheat and maize

\begin{tabular}{|c|c|c|c|c|c|}
\hline Location & Crop & Min. & Max. & Avg. & $\mathbf{I}_{\text {cg }}$ Class \\
\hline $\begin{array}{c}\text { Mingora } \\
\text { (Swat) }\end{array}$ & Wheat & 0.98 & 1.33 & 1.20 & Adequate \\
\hline & Maize & 0.59 & 0.90 & 0.73 & $\begin{array}{c}\text { Moderately } \\
\text { Adequate }\end{array}$ \\
\hline
\end{tabular}

\section{Crop Growth Index (I $\mathrm{cg}$ ) of Maize}

(Table 5) presents the classes of the selected locations. The maximum $\mathrm{I}_{\mathrm{cg}}(0.73)$ and minimum (0.59) of maize was calculated for Mingora (Swat). On the basis of $I_{\mathrm{cg}}$ limits Mingora Swat were classified as Moderately Adequate. These results are in conformity with Roohi et al. [5] who also determined that the available GDD at the selected locations $\backslash$ were Moderately Adequate. The temperature was high in the month of Jun and July. The climate of selected location was suitable for the growth of maize.

\section{Conclusions}

The GDD of wheat crop showed an increasing trend and the GDD of maize crop showed a decreasing trend in Mingora swat. Based on the $\mathrm{I}_{\mathrm{cg}}$ limits Mingora Swat was classified as adequate for wheat and moderately adequate for maize crop.

\section{Authors' contributions}

Conceived and designed the experiments:

R Khan \& ZU Sohail, Performed the experiments: R Khan \& T Jan, Analyzed the data: R Khan \& F Nawaz, Contributed materials/ analysis/ tools: J Ahmad \& SU Hassan, Wrote the paper: N Khan.

\section{References}

1. Chaudhry QZ \& G Rasul (2004). AgroClimatic Zoning of Pakistan. Quat Sci $\operatorname{Rev}$ 9(1-2): 59-66.
2. IPCC(2001). Climate Change : Impacts, Adaptation and Vulnerability. Cambridge University Press, IPCC, New York, USA 1-8.

3. Salma S, Rehman S \& Shah MA (2012). Rainfall Trends in Different Climate Zones of Pakistan. Pak J Metorol 9(17): 37-47.

4. Abendroth LJS, Elmore RW, Boyer MJ\&Marlay SK(2011). Corn Growth and Development. PMR 1009. Iowa State University Extension. Ames, Iowa.

5. Roohi R, AhmadS\& Arshad (2002). Characterization and Classification of Agro-Climates of Pakistan. Pak J Agric Res 17(3): 1-18.

6. Reas D, Steuto P, Hsiao TC\&Fereres E (2009). Aqua Crop-The FAO Crop Model to Simulate Yield Response to Water: Concepts and Underlying Principles. Agron J 101(3): 426-437.

7. Gomez KA \& Gomez AA (1984). Statistical Procedure for Agricultural Research. Second Edition. An International Rice Research Institute Book.

8. Huq S, Karim Z, Asaduzzaman M \& Mahtab F (1999). Vulnerability and adaptation to climate change in Bangladesh. Dordrecht: Kluwer. 